\title{
PROTOTIPE PAKAN AYAMOTOMATIS MENGGUNAKAN METODE BACKPROPAGATIONBERBASIS JARINGAN SYARAF TIRUAN
}

\author{
Ramalia Noratama Putri ${ }^{1)}$ Debi Setiawan ${ }^{2)}$ \\ ${ }^{1}$ Sistem Informasi, STIKOM Pelita, Jl. Datuk tunggul Blok D No 10 \\ ${ }^{2}$ Teknik Informatika, STMIK Amik Riau, Jl. Purwodadi Km 10,5 Pekanbaru \\ email: ramalia.noratamaputri@lecturer.pelitaindonesia.ac.id, debisetiawan9090@gmail.com
}

\begin{abstract}
The purpose of this research is to realize the tool of automatic chicken feed based on artificial mesh network to facilitate the company in giving chicken feed without having to interact directly every. Variables used in this study include Chicken Feeding per hour, the ability to eat food perkilogram. capacity out of food per hour. The method used backpropagation because this method is suitable to use the process of reasoning based on the variables used. This research produces an automatic chicken feed prototype in the form of chicken feeding simulation tool which can be developed into the appropriate tool. The results of this system prototype test have accuracy located on the microprocessor chip and sensor system that produces a $0.9 \%$ MSE level and $99.8 \%$ accuracy rate, to the feeding schedule detection.
\end{abstract}

Keywords: Backpropagation, Prototype, Chicken Feed

Abstrak

Tujuan dari penelitian ini adalah untuk merealisasikan alat pakan ayam otomatis berbasis jaringan sayraf tiruan agar memudahkan perusahaan dalam pemberian pakan ayam tanpa harus berinteraksi secara langsung setiap. Variabel yang digunakan dalam penelitian ini antaralain Kapasitas makan ayam perjam, kesanggupan menghabiskan makanan perkilogram, kapasitas keluar makanan perjam.Metode yang digunakan backpropagation karena metode ini cocok digunakan untuk melakukan prosespenalaran berdasarkan variable yang digunakan. Penelitian ini menghasilkan prototipe pakan ayam otomatis berupa alat simulasi pemberian pakan ayam yang dapat dikembangkan menjadi alat tepat guna. Hasil uji prototipe sistem ini memiliki keakurasian yang terletak pada chip microprocessor dan system sensor yang menghasilkan tingkat MSE 0.9\% dan tingkat keakurasian 99.8\%, terhadap deteksi jadwal pemberian pakan.

Keywords:Backpropagation, Prototipe, Pakan Ayam

\section{PENDAHULUAN}

Permasalahan yang sering dihadapi peternak ayam potong adalahtingginya permintaan konsumen terhadap jumlah serta kualitas ayam potong yang dijual.Hal ini menuntut peternak agar lebih mempercepat masa panen ayam sesuai dengan permintaan konsumen. Untuk menjaga kualitas, meningkatkan jumlah, serta mempercepat masa panen dari ayam tersebut salah satu bentuk atau cara yang dilakukan adalah dengan pemberian makanan yang teratur. Salah satunya dengan menciptakan suatu model prototipe pemberian makan otomatis. Prototipe ini berfungsi untuk memberikan makanan ayam secara teratur tanpa harus berinteraksi dengan ayam secara langsung. Peternak cukup meletakan makanan ayam kedalam box penampung makanan ayam dan box akan bekerja secara otomatis untuk memberikan pakan ternak secara terjadwal.

Peneliti sebelumnya yaitu Kholidi N telah melakukan penelitian pemberian makan ayam otomatis berbasis programmable Logic Controller, dengan percent of error rata-rata sebesar $0.313 \%$.

Metode yang digunakan dalam penelitian ini adalah backpropagation. Berdasarkan studi literatur yang telah dilakukan Metode ini sangat tepat digunakan untuk penelitian ini bahwa metode jaringan syaraf tiruan telah banyak diterapkan dalam penelitian, diantaranya dapat dilihat dalam penelitian yang dilakukan oleh Pangastuti. Peneletian tersebut menggunakan metode Jaringan Syaraf Tiruan backpropagation untuk mengukur tingkat korelasi prestasi 
mahasiswa. Berdasarkan hasil penelitian tersebut, tingkat korelasi kecocokan antara target yang telah ditentukan dan targethasil prediksi sebesar 61\% (Fatkuroji,2013). Metode Jaringan Syaraf Tiruan merupakan metode yang tepat untuk digunakan, karena mampu untuk menyelesaikan permasalahan yang kompleks dengan nilai eror terkecil (Sya'diyah, Z, 2015). Ada banyak teknik yang dapat digunakan untuk implementasi Jaringan Syaraf Tiruan yaitu Perceptron, Backpropagation dan Fuzzy. Dalam penelitian ini penulis menggunakan algoritma backropagation. Tahap pelatihan dengan menggunakan metode backpropagation terdiri dari tiga fase, yaitu fase propagasi maju, fase propagasi mundur, dan fase perubahan bobot. Ketiga fase tersebut diulang terus menerus hingga kondisi penghentian dipenuhi. Umumnya kondisi penghentian yang sering dipakai adalah jumlah iterasi atau kesalahan atau target error (Trimulya, A.,2015)

\section{TINJAUAN P USTAKA}

\section{A. Jaringan Syaraf Tiruan}

Jaringan Syaraf Tiruan adalahparadigma pengolahan informasi yangterinspirasi oleh sistem syaraf secarabiologis, seperti proses informasi padaotak manusia. Elemen kunci dariparadigma ini adalah struktur dari sistem pengolahan informasi yang terdiri darisejumlah besar elemen pemrosesan yangsaling berhubungan (neuron), bekerjaserentak untuk menyelesaikan masalahtertentu. Cara kerja JST seperti cara kerjamanusia, yaitu belajar melalui contoh.

Sebuah JST dikonfigurasikan untukaplikasi tertentu, seperti pengenalan polaatau aplikasi data, melalui prosespembelajaran. Belajar dalam sistembiologis melibatkan penyesuaian terhadapkoneksi synaptic yang ada antara neuron.Hal ini berlaku juga untuk JST (T.Sutojo, S.Si,2011)

\section{B. Algoritma Backpropagation}

Backpropagation

adalah metodepenurunan gradient untuk meminimilkankuadrat error keluaran. Ada tiga tahapyang harus dilakukan dalam pelatihanjaringan, yaitu tahap perambatan maju(forward propagation), tahap perambatanbalik, dan tahap perubahan bobot dan bias.Arsitektur jaringan ini tediri dari inputlayer, hidden layer, dan output layer (T.Sutojo, S.Si,2011).

Algoritma

Backpropagationmerupakan salah satu algoritma yangsering digunakan dalam menyelesaikanmasalah-masalah yang rumit. Hal inidimungkinkan karena jaringan denganalgoritma ini dilatih dengan menggunakanmetode belajar terbimbing. Pada jaringandiberikan sepasang pola yang teridiri dariatas pola masukan dan pola yangdinginkan (Matondang,2013).Tahap pelatihan dengan menggunakanmetode backpropagation terdiri dari tigafase,yaitu fase propagasi maju, fasepropagasimundur, dan fase perubahanbobot. Ketiga fase tersebut diulang terusmenerus hingga kondisi penghentiandipenuhi. Umumnya kondisi penghentianyang sering dipakai adalah jumlah iterasiatau kesalahan atau target error (Trimulya, A.,2015).

Sebelum dilakukan pelatihan danpengujian pada perhitungan prediksimenggunakan metode JST maka terlebihdahulu data yang akan dilatih dan diujiditransformasikan. Tahapan transformasimerupakan tahapan untuk merubah datareal menjadi data yang dibutuhkan dalampelatihan Jaringan Syaraf Tiruan. Datayang akan dimasukkan pada JaringanSyaraf Tiruan harus dinormalisasi terlebihdahulu. Proses normalisasi akan dilakukanterhadap input dan target.

Prosesnormalisasi ini berguna supaya JaringanSyaraf Tiruan dapat mengenali datasehingga data-data input dan target yangtelahditentukan masuk dalam suatu rangetertentu sehingga proses training padaJaringan Syaraf Tiruan bisa lebih efektifserta efesien. Dalam kasus ini data akanditransformasikan pada interval $[0,1$ 0,9 ]mengingat fungsi sigmoid merupakanfungsi asimtotik yang nilainya tidak pernahmencapai 0 ataupun 1 .

Untukmentransformasikan seluruh data realtersebut, digunakan fungsi sebagaiberikut

y $1=0.8(x-b)(c-b)+0.1(1)$

Di mana:

$\mathrm{a}=$ data minimum

$\mathrm{b}=$ data maksimum

$\mathrm{x}=$ nilai asli dari data

x $1=$ nilai transformasi dari data 
Algoritma pelatihan untuk jaringansyaraftiruan Backpropagation ini adalahsebagai berikut :Langkah 0 : Inisialisasi bobot dengan nilairandom atau acak yang cukup kecil. Setlearning rate $\alpha(0<\alpha<=1)$

Algoritma pelatihan untuk jaringan saraf tiruan Backpropagation ini adalah sebagai berikut :

Langkah 0 : Inisialisasi nilai bobot dengan nilai acak yang kecil.

Langkah 1 : Selama kondisi berhenti masih tidak terpenuhi, laksanakan langkah 2 sampai 9.

Langkah 2 : Untuk tiap pasangan pelatihan, kerjakan langkah 3 sampai 8 .

a. Feedforward :

Langkah 3 : Untuk tiap unit masukan $(X i, \quad i=1, \ldots, n) \quad$ menerima sinyal masukan $x i$ dan menyebarkan sinyal itu ke seluruh unit pada lapis atasnya (lapis tersembunyi).

Langkah $4 \quad$ : Untuk tiap unit tersembunyi $(Z j, j=1, \ldots, p)$ dihitung nilai masukan dengan menggunakan nilai bobotnya $Z_{-} i n_{j}=V o_{j}+\sum_{i=1}^{n} \quad X_{I} V_{i j}$ Kemudian dihitung nilai keluaran dengan menggunakan fungsi akti-vasi yang dipilih :

$z_{j}=f\left(z_{i n_{j}}\right)$ di mana fungsi aktivasi yang digunakan ialah fungsi sigmoid biner yang mempunyai persamaan :

$$
f 1(x)=\frac{1}{1+\exp (-z)}
$$

Hasil fungsi tersebut dikirim ke semua unit pada lapis di atasnya.

Langkah 5 : Untuk tiap unit keluaran $\left(y_{k}, k=1, . ., m\right)$ dihitung nilai masukan dengan menggunakan nilai bobot-nya

$$
\begin{aligned}
& y_{\left(i n_{k}\right.} \\
& =W_{o k}+\sum_{i=1}^{p} Z_{j} W j k
\end{aligned}
$$

Kemudian dihitung nilai keluaran dengan menggunakan fungsi aktivasi :

$$
y_{k}=\frac{1}{1+\exp (-y)}
$$

b. Perhitungan backward :

Langkah 6 : Untuk tiap unit keluaran $\left(y_{k}, k=1, . ., m\right)$ menerima pola target yang bersesuaian dengan pola masukan, dan kemudian dihitung informasi kesalahan :

$$
\sigma_{k}=\left(t_{k}-y_{k}\right) f^{\prime}\left(y_{-i n_{k}}\right)
$$

Kemudian dihitung koreksi nilai bobot yang kemudian akan digunakan untuk memperbaharui nilai bobot wjk.:

$$
\Delta W_{j k}=\alpha \delta_{k} z_{j}
$$

Hitung koreksi nilai bias yang kemudian akan digunakan untuk memperbaharui nilai $W_{0 k}$ :

$$
\Delta W_{0 k(5)}=\alpha \delta_{k}
$$

dan kemudian nilai $\delta \mathrm{k}$ dikirim ke unit pada layer sebelumnya.

Langkah $7 \quad$ : Untuk tiap unit tersembunyi $(Z j, j=1, \ldots, p)$ dihitung delta masukan yang berasal dari unit pada layer di atasnya :

$$
\delta_{i n_{j}}=\sum_{k=1}^{m} \delta_{k} W_{j k}
$$

Di mana nilai tersebut dikalikan dengan nilai turunan dari fungsi aktivasi untuk menghitung informasi kesalahan :

$$
\delta_{j}=\delta_{i n_{j}} f^{\prime}\left(z_{i n_{j}}\right)
$$

Hitung koreksi nilai bobot yang kemudian digunakan untuk me perbaharui nilai vij: $\Delta V_{i j}=\alpha \delta_{j} X_{i}$ 
dan hitung nilai koreksi bias yang kemudian digunakan untuk memperbaharui voj:

$$
\Delta V_{0 j}=\alpha \delta_{j}
$$

c. Memperbaharui nilai bobot dan bias :

Langkah 8 : Tiap nilai bias dan bobot $(j=0, \ldots, p)$ pada unit keluaran $\left(y_{k}, k=1, \ldots, m\right)$ diperbaharui : $W_{j k}($ new $)=W_{j k}($ old $)+$ $\Delta W_{j k}$ $V_{i j}($ new $)=V_{i j}($ old $)+\Delta V_{i j}$

Langkah $9 \quad$ : Menguji apakah kondisi berhenti sudah terpenuhi. Kondisi berhenti ini terpenuhi jika nilai kesalahan yang dihasilkan lebih kecil dari nilai kesalahan referensi.

\section{Pakan Ternak Otomatis}

Variabel yang digunakan dalam penelitian ini antara lain :

1. Kapasitas makan ayam perjam

2. Kesanggupan menghabiskan makanan perkilogram

3. Kapsitas keluar makanan per jam

Pemberian pakan ternak ini mempunyai tujuanuntuk memberikan kemudahan bagi peternak untuk memberikan pakan tanpa harus berinteraksi langsung dengan ayam potong.

\section{METODE PENELITIAN}

Gambaran tahapan penelitian :

1. Identifikasi masalah

Permasalahan dalah penelitian iniadalah,bagaimana cara memeberikan pakan ayam secara teratur tanpa berinteraksi langsung. Untukmenyelesaikan masalah tersebutpenulis menggunakan jaringansyaraf tir(u@a) dengan algoritmabackpropagation)

2. Kajian Pustaka

Setelah masalah dalam penelitiandianalisa, langkah selanjutnya yangdilakukan peneliti adalah melakukan studi literartur, yaitu membandingkan metode perhitungan yang telah dilakukan oleh peneliti sebelumnya, kelemahan dan keunggulan dari metode yang kita gunakan.

3. Pengambilan data

Mengumpulkan

dataProsespengumpulan data terbagi menjadidua yaitu data kuantitatif yaitu datayang kita dapatkan berdasarkanangka. Hal ini berguna untuk proses perhitungan ketepatan dalam waktu pemberian pakan ayam permasing-masing kandang. Data yangdikumpulkan adalahkapasitas makan/ jam, kesanggupan menghabiskan makanan/ jam, kapasitas keluar makanan/ jam di tengki pakan ayam. 


\begin{tabular}{|c|c|c|c|c|c|c|c|c|c|}
\hline NO KANOANG & $\begin{array}{l}\text { IODWNAL } \\
\text { PEMBCTIAN } \\
\text { PAKAN } \\
\text { AYAM }\end{array}$ & $10 \mathrm{M}$ & $\begin{array}{l}\text { JUMLAH AYAM } \\
\text { /EKOR }\end{array}$ & $\begin{array}{c}\text { IEDAR } \\
\text { KANOANG }\end{array}$ & $\begin{array}{l}\text { LAMA } \\
\text { PANEN } \\
\text { GULAN }\end{array}$ & PMKAN AYAM & $\begin{array}{l}\text { RAPASITAS } \\
\text { MAKAN }\end{array}$ & $\begin{array}{l}\text { KESANGGUPAN } \\
\text { MENGHABISKAN } \\
\text { MAKANAN/KO }\end{array}$ & $\begin{array}{c}\text { KAPASTAS } \\
\text { KELUAR } \\
\text { MAKANAN/IAM }\end{array}$ \\
\hline \multirow[b]{2}{*}{1} & Pagi & $56 / 00$ & \multirow{2}{*}{350} & \multirow{2}{*}{$3 \times 3$} & \multirow{2}{*}{2} & Makanen & 8 & 25 & 3.13 \\
\hline & Sare & $16: 80$ & & & & Makaran + Vaksin & 8 & 20 & 2.50 \\
\hline \multirow[b]{2}{*}{2} & Pagi & $50: 80$ & \multirow{2}{*}{120} & \multirow{2}{*}{$2 \times 2$} & \multirow{2}{*}{2} & Makanen & 8 & 10 & 1.25 \\
\hline & Sore & $16: 20$ & & & & Makaran + Vaksin & 8 & 25 & 3.13 \\
\hline \multirow[b]{2}{*}{3} & Pagi & 50.80 & \multirow{2}{*}{400} & \multirow{2}{*}{$3 \times 3$} & \multirow{2}{*}{2} & Makanan & 8 & 35 & 4.36 \\
\hline & Sore & $16: 20$ & & & & Makaran I Vaksin & 0 & 20 & 2.50 \\
\hline \multirow[b]{2}{*}{4} & Pagi & $80 / 80$ & \multirow{2}{*}{250} & \multirow{2}{*}{$3 \times 1$} & \multirow{2}{*}{2} & Makanen & 8 & 22 & 275 \\
\hline & Sore & $16: 20$ & & & & Makeran + Vaksin & 0 & 15 & 2.36 \\
\hline \multirow[b]{2}{*}{5} & Pagi & $80: 20$ & \multirow{2}{*}{180} & \multirow{2}{*}{$2 \times 2$} & \multirow{2}{*}{2} & Makanen & 8 & 20 & 250 \\
\hline & Sore & $16 \% 0$ & & & & Makbnan + Vaksin & 0 & 10 & 2.38 \\
\hline \multirow[b]{2}{*}{6} & Pagi & $60: 80$ & \multirow{2}{*}{275} & \multirow{2}{*}{$3 \times 3$} & \multirow{2}{*}{2} & Makanen & 8 & 25 & 3.63 \\
\hline & Sore & $16 / 00$ & & & & Makanan + Vaksin & 0 & 17 & 2.13 \\
\hline \multirow[b]{2}{*}{7} & Pagi & 80.80 & \multirow{2}{*}{ 13) } & \multirow{2}{*}{$2 \times 2$} & \multirow{2}{*}{2} & Makanen & 8 & 15 & 188 \\
\hline & Sore & 16.00 & & & & Mekaran + Veksin & 0 & 15 & 188 \\
\hline & & & & & & $\begin{array}{l}\text { Kesil } \\
\text { darih } \\
\text { sudal }\end{array}$ & $\begin{array}{l}\text { ulan } \\
\text { il }\end{array}$ & $\begin{array}{l}\text { merupaka } \\
\text { penelitian }\end{array}$ & $\begin{array}{r}\text { ben } \\
\text { ya }\end{array}$ \\
\hline
\end{tabular}

Keterangan :

$\mathrm{X} 1=$ Kapasitas Makan/Jam

$\mathrm{X} 2=$ Kesanggupan menghabiskan makanan / Jam

X3= Kapasitas keluar makanan / Jam Untuk mencari $\mathrm{X} 3=\mathrm{X} 2 / \mathrm{X} 1$

4. Perhitungan Manual

Proses perhitungan secara manualdengan menggunakan algoritmabackpropagation

5. Perancangan Pola JST

Pada proses ini, kita dapatmenentukan Pola Jaringan SyarafTiruan berdasarkan variabel.

6. Perhitungan JST

Proses pelatihan dan pengujian polaJST. Pada proses ini setiap variabel yang kita gunakan nantinya akankita lakukan proses pelatihan danpengujian agar mendapatkan polaterbaik dengan nilai eror terkecil.

7. Pengujian Prototipe JST

Cara melihat sistem mampu merealisasikan tujuan sebagai alat deteksi banjir dengan cara mensimulasikannya, dan melihat cara kerja alat sesuai atau tidak.

8. Evaluasi Prototipe JST

Evaluasi terhadap hasil perhitungan dengan jaringan syraf tiruan menggunakan algoritma backpropagation yaitu apakah jaringan syraf tiruan dapat memberikan makan ayam secara otomatis

9. Kesimpulan

\section{ImplementasiAlgoritmaBackpropagation}

1. Proses Normalisasi

Proses normalisasi merupakan suatulangkah kerja dalam mememindahkanangka dari kolom menjadi baris dan dari bilangan bulat menjadi pecahan, hal ini dilakukan agar data tadi mudah untuk dilakukan proses perkalian bobot pada matlab karna memiliki angka pecahan atau dinormalisasikan.

2. Data Input dan Target

Sebelum proses pegolahan datadilakukan, perlu dilakukan proses penetuanmasukan (input) serta target atau hasilyang diinginkan dari proses pengolahandata, berikut data input dan targetberdasarkan data beban kerja dosen yangtelah dikumpulkan, sampel yang diambil7 sampel kandang.

\section{HASIL DAN PEMBAHASAN}

Hasil dari sistem yang dibuat dapat dilihat sebagai berikut : 


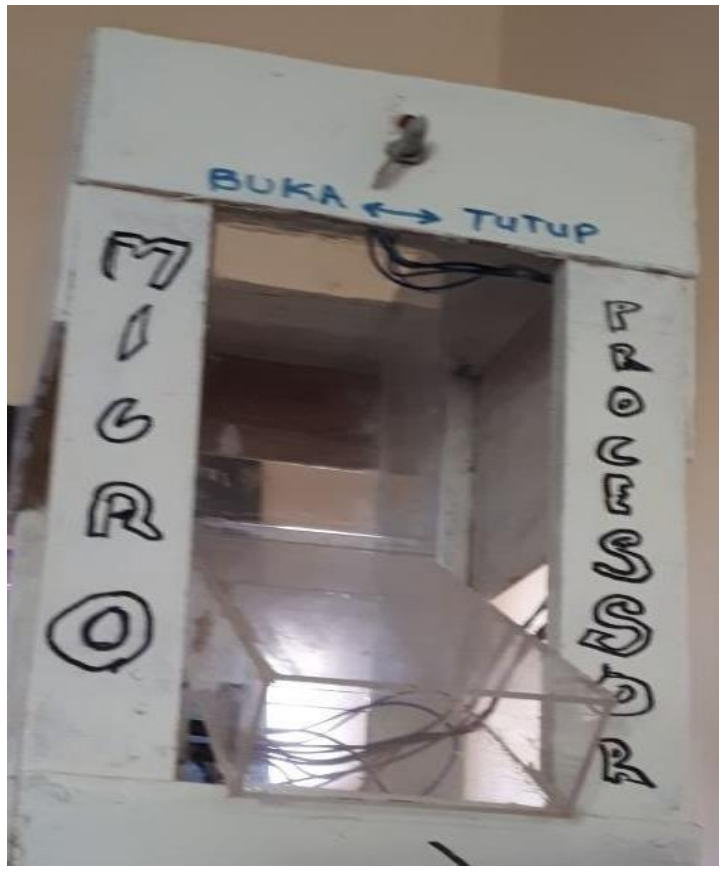

Gambar 1. Bentuk Prototipe pemberi makanan ayam otomatis
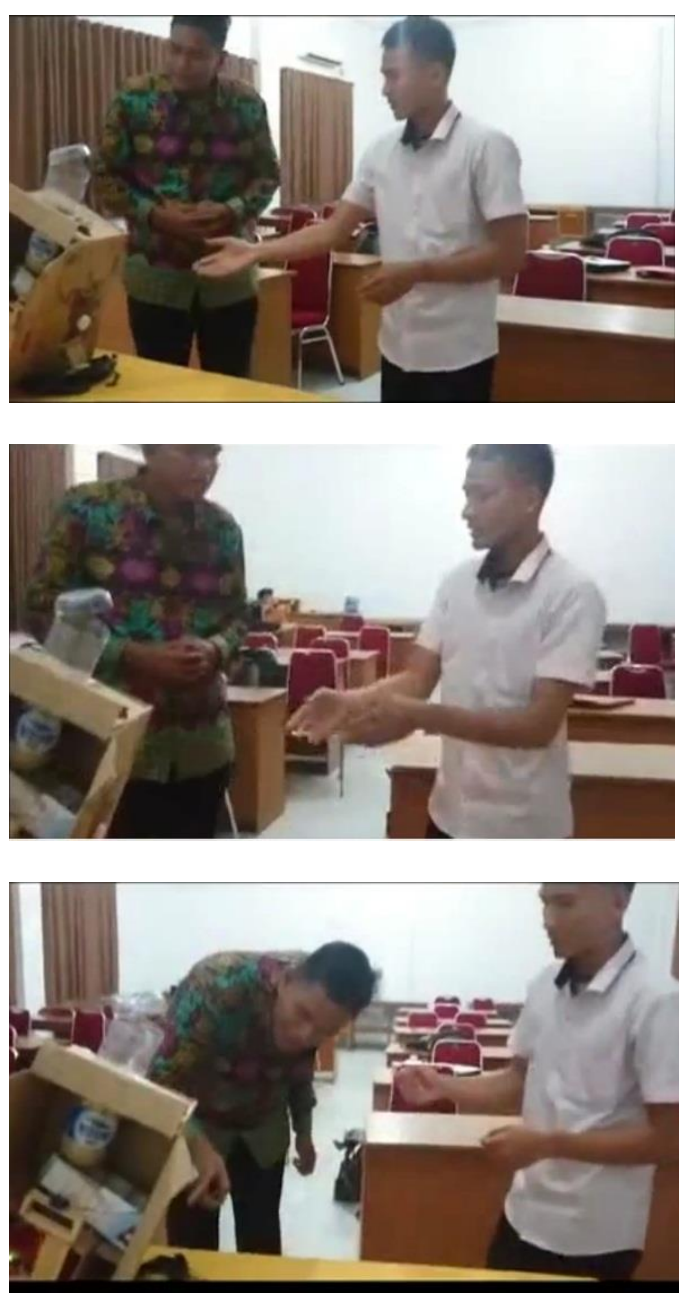
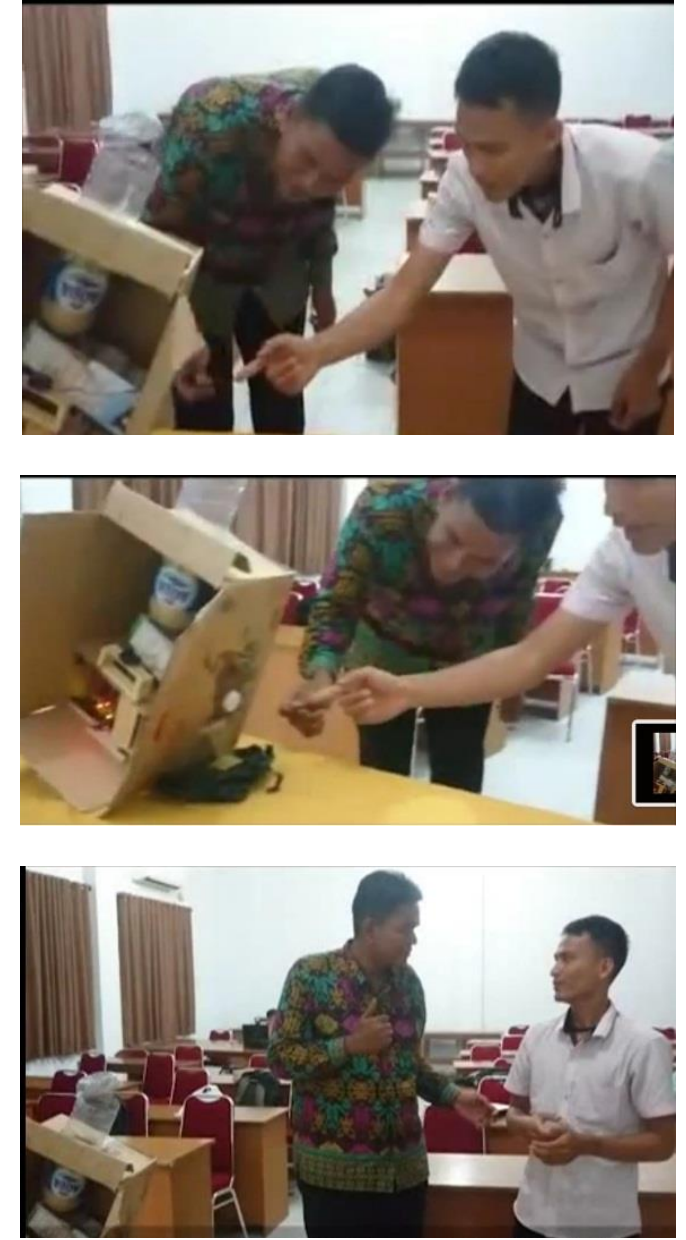

Gambar 2. Pengujian Alat Oleh Peneliti, disaksikan oleh mahasiswa

Pembahasan dari sistem yang dibuat ini antaralain penerapan dari metode yang digunakan untuk mendukung dari ketepatan proses pengujian sistem sehingga saat dijalankan.

\section{SIMPULAN}

Berdasarkan hasil dan implementasi, didapat kesimpulan bahwa jaringan syaraf tiruan menggunakan algoritma backpropagation dapat diterapkan dalam prototipe pakan ayam otomatis, hal ini dapat dilihat dengan error yang mendekati 0.1 .

\section{UCAPAN TERIMAKASIH}

Terimakasih kepada manajemen PT. Subur Jaya.Tbk, serta pengelola jurnal STIKOM Pelita yang sudah menerbitkan jurnal ini. 


\section{DAFTAR PUSTAKA}

Fatkuroji. (2013). AnalisisDeterminasi Minimnya Minat DosenDalam Penelitian Fatkuroji, 4, 33-50.

Pangastuti, P. (2010). UntukMengukur Tingkat Korelasi PrestasiMahasiswa ( Studi Kasus PadaUniversitas Dian NuswantoroSemarang ).

Sya'diyah, Z. (2015). No Title NoTitle. Statewide Agricultural LandUse Baseline 2015, 1.http://doi.org/10.1017/CBO97811074 15324.004

Trimulya, A., Setyaningsih, F. A.,Komputer, J. S., Elektro, J. T.,Teknik, F., \& Tanjungpura, U.(2015). Implementasi jaringan syaraftiruan metode backpropagationuntuk memprediksi harga saham 1,3,03(2), 66-75.

T.Sutojo, S.Si, M. K., Edy Mulyanto,S.Si, M. K., \& Suhartono, D. V.(2011). Kecerdasan Buatan. InKecerdasan Buatan (1st ed., p. 466).yogyakarta: Andi.

Matondang, Z. A., Tiruan, S.,Mengukur, U., Korelasi, T., Syaraf, J., Dengan, T., ...Penentuan, U.(2013). Jaringan Syaraf TiruanDengan Algoritma. 